10 Government Statistical Service. Hospital episode statistics, 1989-1990. London: HMSO, 1993.

11 Gill L, Goldacre M, Simmons H, Bettley G, Griffith M. Computerised linking of medical records: methodological guidelines. I Epidemiol Community Health 1993;47:316-9.

12 Majeed FA, Voss S. Performance indicators for general practice [editorial]. BMJ 1995;311:209-10.

13 Majeed FA. Deprivation payments to general practitioners [letter]. BMJ 1995;310:1674.

14 Majeed FA, Cook DG, Poloniecki J, Martin D. Using data from the 1991 census. BMJ 1995;310:1511-4.

15 Gardner M, Altman D, eds. Statistics with confidence: confidence intervals and statistical guidelines. London: BMJ Publishing, 1989.

16 Sloggett A, Joshi H. Higher mortality in deprived areas: community or personal disadvantage? BMJ 1994;309:1470-4.

17 Laing's review of private health care, 1995. London: Laing and Buisson, 1996.
18 Lamden KH, Sudell AJ. Access to elective surgery at electoral ward level: the impact of the private sector.J Public Health Med 1995;17:63-4.

19 Blaxter M. Equity and consultation rates in general practice. $B M J$ 1984;288:1963-7.

20 Calle EE, Flanders WD, Thun MJ, Martin LM. Demographic predictors of mammography and Pap smear screening in US women. Am J Public Health 1993:83:53-60.

21 Chaturvedi N, Ben-Shlomo Y. From the surgery to the surgeon: does deprivation influence consultation and operation rates? Br J Gen Pract 1995;45:127-31.

22 Billings J, Zeitel L, Lukomnik J, Carey TS, Blank AE, Newman L. Impact of socioeconomic status on hospital use in New York City. Health Affairs $1993 ; 12: 162-73$

23 Carstairs V, Morris R. Deprivation and health in Scotland. Health Bull $1990 ; 48: 162-75$

24 Eames M, Ben-Shlomo Y, Marmot MG. Social deprivation and premature mortality: regional comparison across England. BMJ 1993;307:1097-102. (Accepted 16 April 1998)

\title{
Mortality in people taking selegiline: observational study
}

\author{
Margaret Thorogood, Ben Armstrong, Tom Nichols, Jen Hollowell
}

\section{Health Promotion Research Unit, \\ London School of Hygiene and \\ Tropical Medicine \\ London \\ WC1E 7HT \\ Margaret \\ Thorogood, \\ reader in public \\ health and \\ preventative medicine \\ Tom Nichols, \\ research assistant \\ Environmental \\ Epidemiology Unit, \\ London School of \\ Hygiene and \\ Tropical Medicine \\ Ben Armstrong, \\ senior lecturer in \\ medical statistics \\ Office for National \\ Statistics, London \\ SW1V 2QQ \\ Jen Hollowell, \\ General Practice \\ Research Database \\ research manager \\ Correspondence to: Dr Thorogood \\ m.thorogood@lshtm. \\ ac.uk}

BMJ 1998;317:252-4

\begin{abstract}
Objective: To evaluate mortality among patients with Parkinson's disease receiving different treatment.

Design: Cohort study based on computerised medical records.

Setting: UK General Practice Research Database. Subjects: 12621 patients aged between 35 and 90 years who had received a prescription for an antiparkinsonian drug, whether or not a diagnosis of Parkinson's disease had been recorded. Patients prescribed an antipsychotic drug before or at the same time as their first antiparkinsonian drug or before age 35 were excluded to avoid including drug-induced Parkinsonism.

Main outcome measure: Death from any cause. Results: 1720 deaths occurred during 14000 person-years of observation. There was a non-significant $11 \%$ (95\% confidence interval $0 \%$ to $23 \%$ ) increase in the risk of death associated with taking selegiline either alone or in combination with levodopa. The death rate was higher among younger patients (aged under 80 years) and those with a recorded diagnosis of Parkinson's disease taking selegiline alone.
\end{abstract}

Conclusions: The results are compatible with a small excess mortality in people taking selegiline and suggest a larger excess in patients under 80 years of age and those with a confirmed diagnosis of Parkinson's disease taking selegiline without levodopa.

\section{Introduction}

The Parkinson's Disease Research Group trial of drug treatments for Parkinson's disease began in 1985 following earlier indications of a beneficial effect of selegiline. The trial included 822 patients with early Parkinson's disease randomised into one of three treatment arms: levodopa and dopa decarboxylase inhibitor (arm 1), levodopa and dopa decarboxylase inhibitor combined with selegiline (arm 2), and bromocriptine (arm 3). ${ }^{1}$ A pre-planned interim analysis in December 1994 revealed a significant difference in mortality between arms 1 and 2, and the group decided to stop treating patients with selegiline and to publish these results. There was an average of 5.6 years follow up, and the mortality hazard ratio comparing arm 2 with arm 1 was 1.57 (95\% confidence interval 1.07 to 2.31) after adjustment for age, sex, level of disability before treatment, duration of Parkinson's disease, and year of entry to the trial. ${ }^{2}$

After the publication of these results we were asked by the Medicines Control Agency to evaluate mortality among patients taking antiparkinsonian drugs whose medical records were included in the General Practice Research Database.

\section{Methods}

The General Practice Research Database is a longitudinal dynamic database of medical records collected from a panel of general practitioners throughout the United Kingdom. Anonymised patient records are collected regularly from around 500 participating practices providing information on drug treatment, diagnoses, and important clinical events. There are around 3.5 million patients currently registered on the database. The database has been widely used and validated in a range of studies. ${ }^{3}$

Patients registered with a participating practice who were aged between 35 and 90 years and who had received at least one prescription for an antiparkinsonian drug, whether or not a diagnosis of Parkinson's disease had been recorded, were eligible for inclusion. Patients prescribed an antipsychotic drug before or at the same time as their first antiparkinsonian drug and patients prescribed an antiparkinsonian drug before age 35 were excluded to avoid including drug-induced parkinsonism. Age, sex, aspects of medical history, a detailed history of the prescription of antiparkinsonian or antipsychotic drugs, and the fact and date of death were collected. We started follow up on the date a patient's practice began submitting data (earliest in 1987) or when a patient joined the practice, if later, and we ended it six months before the last data collection from the practice (usually in 1996) or when a patient left the prac- 
tice, to allow time to confirm whether patients were alive should there be no record of a death before that date.

Patients' time under observation was divided into treatment groups, with the operational rule that a patient began taking the drug prescribed on the day of prescription and stopped on the day of the next prescription for the same drug type or 60 days after prescription, whichever came first. We report here the results for the three treatment groups of levodopa (with dopa decarboxylase inhibitor), selegiline, and selegiline in combination with levodopa. Time during which patients took other antiparkinsonian drugs was excluded from this analysis. The treatment history before a patient's practice began submitting data was not known.

Follow up was further divided by potential confounding or modifying factors that vary with time: age, calendar year, diagnosis group (record of a diagnosis of Parkinson's disease or not), previous use of any antidepressants, concurrent prescription for a tricyclic antidepressant, concurrent prescription for a selective serotonin reuptake inhibitor, history of cerebrovascular disease, and history of ischaemic heart disease.

Death rates by treatment were calculated by dividing the number of deaths by the total person-time of observation of patients taking a specific drug or combination of drugs. Poisson regression analysis was used to obtain rate ratios with adjustment for potentially confounding variables.

\section{Results}

A total of 12621 patients with a mean age of 72.5 years (range 35 to 89 ) were included in the study with a mean follow up of 1.7 years. The prevalence of patients with a record of taking antiparkinsonian drugs in the database varied between 18.5 and 19.0 per 10000 . Sixty per cent of the patients (7588) were already taking antiparkinsonian drugs at the start of their follow up; $9196(73 \%)$ had a diagnosis recorded, of whom 8937 (97\%) had Parkinson's disease. The standardised mortality ratio for the whole cohort compared with the population of England and Wales was 2.02 (2163 deaths; $95 \%$ confidence interval 1.94 to 2.11 ), an overall death rate of 11 per 100 patient years. There were 1720 deaths in patients taking one of the three treatments included in this analysis during about 14000 person years of observation.

In all, 8708 (69\%) patients received only one drug or combination of drugs during the period of follow up. Table 1 shows the mortality ratios by treatment group adjusted for age and sex and 10 other potential confounding factors. There was a 11\% (95\% confidence interval $0 \%$ to $23 \%$ ) increase in the risk of death associated with using selegiline either alone or in combination with levodopa compared with using levodopa alone. However, there was a significant interaction of treatment group with age $(\mathrm{P}=0.005)$ and with diagnosis $(\mathrm{P}=0.006$ - code simplified to parkinsonism $v$ other or none).

Table 2 shows the mortality ratios by treatment group compared with the levodopa alone group stratified into age and diagnosis groups. These interactions reflected variations in the rate ratios for using selegiline alone. There is little evidence that rate ratios for selegiline with levodopa were affected. There was a higher death rate among younger patients (aged under 80 years) taking selegiline alone, which was significant in those aged 70-79 years. The association of mortality with use of selegiline on its own was positive (and significant) in patients with a recorded diagnosis of Parkinson's disease and negative in those without such a record.

\section{Discussion}

Our large cohort study includes more than 14000 person-years of observation. The observed doubling of risk of mortality in these patients is similar to that observed in a smaller cohort study of elderly people (aged over 65 years) with parkinsonian symptoms in New England. ${ }^{4}$ The prevalence of users of parkinsonian drugs in our cohort (18-19 per 10000$)$ was slightly greater than the prevalence of 15 per 10000 consulting for Parkinson's disease reported in the general practice morbidity study, ${ }^{5}$ which may indicate that a minority of our patients did not have Parkinson's

Table 1 Mortality of patients with Parkinson's disease by drug use

\begin{tabular}{|c|c|c|c|c|}
\hline \multirow[b]{2}{*}{ Treatment group } & \multirow{2}{*}{$\begin{array}{c}\text { Person-time } \\
\text { of observation } \\
\text { (years) }\end{array}$} & \multirow[b]{2}{*}{$\begin{array}{l}\text { No of } \\
\text { deaths }\end{array}$} & \multicolumn{2}{|c|}{ Mortality ratio $(95 \% \mathrm{Cl})$} \\
\hline & & & $\begin{array}{l}\text { Adjusted for } \\
\text { age and sex }\end{array}$ & $\begin{array}{c}\text { Full } \\
\text { adjustment }\end{array}$ \\
\hline Levodopa alone & 9028.0 & 1124 & 1.00 & 1.00 \\
\hline Selegiline alone & 1118.3 & 136 & 1.13 (0.95 to 1.35$)$ & 1.14 (0.95 to 1.36$)$ \\
\hline Selegiline with levodopa & 4102.0 & 460 & $1.12(1.00$ to 1.25$)$ & 1.10 (0.98 to 1.23$)$ \\
\hline Selegiline alone or with levodopa & 5220.3 & 596 & 1.12 (1.01 to 1.24$)$ & $1.11(1.00$ to 1.23$)$ \\
\hline
\end{tabular}

${ }^{*}$ Adjusted for age, sex, calendar year, smoking habit, regional health authority, diagnosis group, use of antidepressants (and specifically tricyclics and serotonin reuptake inhibitors), history of cerebrovascular disease, history of ischaemic heart disease, and incident or prevalent disease at entry to study.

Table 2 Effect of treatment on mortality in patients with Parkinson's disease: age and diagnosis subgroup analysis

\begin{tabular}{|c|c|c|c|}
\hline \multirow[b]{2}{*}{ Group } & \multirow{2}{*}{$\begin{array}{l}\text { No of } \\
\text { deaths }\end{array}$} & \multicolumn{2}{|c|}{ Mortality ratio $(95 \% \mathrm{CI})$} \\
\hline & & Age and sex adjusted & Fully adjusted* \\
\hline \multicolumn{4}{|l|}{ Age $35-59$ years } \\
\hline Levodopa & 5 & 1 & 1 \\
\hline Selegiline & 0 & - & - \\
\hline Selegiline plus levodopa & 0 & - & - \\
\hline \multicolumn{4}{|l|}{ Age 60-69 } \\
\hline Levodopa & 36 & 1 & 1 \\
\hline Selegiline & 11 & 1.68 & 1.88 (0.95 to 3.68$)$ \\
\hline Selegiline plus levodopa & 23 & 0.88 & 0.99 (0.58 to 1.67$)$ \\
\hline \multicolumn{4}{|l|}{ Age 70-79 } \\
\hline Levodopa & 343 & 1 & 1 \\
\hline Selegiline & 61 & 1.49 & 1.49 (1.13 to 1.97$)$ \\
\hline Selegiline plus levodopa & 185 & 1.19 & 1.21 (1.01 to 1.45$)$ \\
\hline \multicolumn{4}{|l|}{ Age 80-89 } \\
\hline Levodopa & 740 & 1 & 1 \\
\hline Selegiline & 64 & 0.89 & $0.90(0.70$ to 1.17$)$ \\
\hline Selegiline plus levodopa & 252 & 1.12 & 1.07 (0.92 to 1.23$)$ \\
\hline \multicolumn{4}{|c|}{ No recorded diagnosis of Parkinson's disease } \\
\hline Levodopa & 187 & 1 & 1 \\
\hline Selegiline & 16 & 0.60 & 0.58 (0.34 to 0.97$)$ \\
\hline Selegiline plus levodopa & 35 & 1.19 & 1.11 (0.77 to 1.61$)$ \\
\hline \multicolumn{4}{|c|}{ Recorded diagnosis of Parkinson's disease } \\
\hline Levodopa & 937 & 1 & 1 \\
\hline Selegiline & 120 & 1.25 & 1.30 (1.07 to 1.58$)$ \\
\hline Selegiline plus levodopa & 425 & 1.15 & 1.11 (0.98 to 1.24$)$ \\
\hline
\end{tabular}


disease. As described above, $27 \%$ of patients did not have any diagnosis recorded and 3\% of the remainder had a diagnosis other than Parkinson's disease. When subjects were separated into those with and without a diagnosis of Parkinson's disease the effect of taking selegiline alone differed in the two groups but was the same for those taking selegiline with levodopa (table 2).

\section{Reliability of results}

If the severity of the disease was associated with use of selegiline, the resulting confounding would have been only partially controlled for by adjusting for our only available marker of Parkinson's severity-antidepressant use-which was strongly associated with mortality. Because patients were recruited into the cohort at varying times during their treatment we were unable to adjust further for the length of treatment.

Socioeconomic status could also have been a residual confounder. However, the association of socioeconomic status with use of selegiline would have to be very substantial to account for much residual confounding, especially after adjustment for confounding by smoking habit. Furthermore, mortality gradients by socioeconomic status are diminished at older ages; in 1971-81 the standardised mortality ratio for social classes I and II was 0.82 and that for social classes IV and V was 1.09-a ratio of $0.75 .^{6}$ Adjustment for the confounders we were able to measure made only small changes to the treatment comparisons, which reduced the likelihood of substantial residual confounding.

Irregular use of the prescribed drugs could reduce the observed relative risks, but the nature of the disease, with a dependence on regular treatment to control unpleasant symptoms, is such that use of drugs is likely to be more regular than that for many other diseases.

We did not find the $50 \%$ increased mortality risk in people taking selegiline in combination with levodopa which was observed in the Parkinson's Disease Research Group trial, although we did find an increased risk associated with use of selegiline without levodopa in younger patients (aged under 80 years) and in patients with a recorded diagnosis of Parkinson's disease. The subjects in this study differed from those in the trial in three important respects. Firstly, patients recruited to the trial were all being treated in specialist hospital clinics whereas our patients were selected from general practice. Secondly, the patients in our study were substantially older, with a mean age of 72.5 years. In the trial the mean age of patients was 62.7 and 63.6 years in arms 1 and 2 respectively. Thirdly, patients in the trial were recruited before they started treatment for Parkinson's disease and followed prospectively whereas in our study patients entered the observation period at varying times during their treatment with antiparkinsonian drugs. The subjects in the trial may have represented a younger subgroup with an earlier onset of symptoms, but we do not know of any hypothesis which suggests that an effect of selegiline use, if present, would be limited to this subgroup.

Our study is, like all observational studies, vulnerable to the distortion of the results by residual confounding. Moreover, the data on individuals were limited; in particular there was no direct information
- A prematurely stopped randomised trial reported a $50 \%$ increase in mortality in subjects treated with selegiline combined with levodopa when compared with subjects treated with levodopa alone.

- This cohort study based on computerised general practice records examined 14000 person-years of use of antiparkinsonian drugs

- There was a non-significant $14 \%$ increase in risk of mortality in subjects taking selegiline alone and a non-significant $10 \%$ increase for subjects taking selegiline with levodopa

- This study provides evidence against there being substantial excess mortality associated with use of selegiline

on the severity of Parkinson's disease or on the social class of the subjects. We were thus unable to adjust fully for the potential confounding effect of these variables and the results should be interpreted with caution.

This study provides evidence against a substantial generalised excess mortality in people taking selegiline. The results are compatible with a small excess and suggest a larger excess in patients under 80 years of age and in patients with a confirmed diagnosis of Parkinson's disease taking selegiline without levodopa.

This work was guided by a steering committee which included the authors of this paper, Professor Christopher Kennard (Charing Cross Hospital), and Dr Tharani Sivananthan (Medicines Control Agency).

Contributors: MT and BA wrote the protocol for the study and the paper. JH extracted the data from the General Practice Research Database and advised on the use of the data. TN carried out the statistical analysis. All authors were involved in managing the analysis. MT is the guarantor.

Funding: This work was supported by an unconditional grant from the Medicines Control Agency.

Conflict of interest: None.

1 Parkinson's Disease Research Group in the United Kingdom. Comparisons of therapeutic effects of levodopa, levodopa and selegiline, and bromocriptine in patients with early, mild Parkinson's disease: three year interim report. BMJ 1993;307:469-72.

2 Lees AJ, on behalf of the Parkinson's Disease Research Group of the United Kingdom. Comparison of therapeutic effects and mortality data of levodopa and levodopa combined with selegiline in patients with early, of levodopa and levodopa combined with selegiln
mild Parkinson's disease. BMJ 1995;311:1602-7.

3 Hollowell J. The General Practice Research Database: quality of morbidity data. Population Trends 1997;87.

4 Bennett DA, Beckett LA, Murray AM, Shannon KM, Goetz CG, Pilgrim DM, et al. Prevalence of parkinsonian signs and associated mortality in a community population of older people. N Engl J Med 1996;334:71-6.

5 McCormick A, Fleming D, Chartlon J, eds. Morbidity statistics from general practice: fourth national study 1991-1992. London: HMSO, 1995. (Series MB5 No 3.)

6 Office of Population Censuses and Surveys. Longitudinal study: mortality and social organisation. London: HMSO, 1990.

\section{Endpiece}

\section{Alternative definitions}

Emetic: A substance which causes the stomach to take a sudden and enthusiastic interest in outside affairs.

Ambrose Bierce, The Cynic's Word Book (1906), subsequently titled The Devil's Dictionary 